\title{
FAKTOR-FAKTOR YANG MEMPENGARUHI HEMOGLOBIN IBU HAMIL TRIMESTER III
}

\author{
Factors Affecting Hemoglobin Levels of Third Trimester Pregnant Women \\ Ika Sumiyarsi' ${ }^{1}$, Angesti Nugraheni' ${ }^{2}$, Sri Mulyani ${ }^{3)}$, Erindra Budi C4) \\ *) Program Studi Kebidanan Program Sarjana Terapan, Fakultas Kedokteran, Universitas Sebelas \\ Maret \\ e-mail: ikasumiyarsi@gmail.com
}

DOI: 10.13057/placentum.v\%vi\%i.22836

\begin{abstract}
ABSTRAK
Latar Belakang: Anemia merupakan salah satu penyebab terbesar angka kematian ibu. Anemia yang terjadi hingga trimester ketiga dapat mempengaruhi keadaan janin dan keberlangsungan persalinan. Diagnosis anemia pada ibu hamil ditegakkan melalui pengukuran kadar hemoglobin dalam darah ibu. Penelitian ini bertujuan untuk mendeskripsikan faktor-faktor yang mempengaruhi kadar hemoglobin pada ibu hamil trimester tiga.

Metode: Penelitian ini menggunakan metode deskriptif kuantitatif. Penelitian ini dilakukan di RW XIX Wilayah Puskesmas Ngoresan Surakarta pada bulan September 2016 dengan 34 responden. Instrumen dalam penelitian ini adalah kuesioner.

Hasil: Kadar $\mathrm{Hb}$ ibu hamil di wilayah Puskesmas Ngoresan mayoritas $>10 \mathrm{gr} / \mathrm{dl}$ atau normal (76.5\%). Faktor dasar yang mempengaruhi kadar $\mathrm{Hb}$ ibu hamil meliputi: pengetahuan mayoritas baik (41.2\%), pendidikan mayoritas pendidikan menengah $(94 \%)$ dan sosial budaya mayoritas tidak pantang makanan (85.3\%). Faktor langsung yang mempengaruhi kadar $\mathrm{Hb}$ ibu hamil meliputi: semua ibu mengonsumsi tablet Fe (100\%), status gizi ibu mayoritas baik (79.4\%), semua ibu tidak memiliki penyakit infeksi (100\%), dan semua ibu tidak mengalami perdarahan (100\%). Faktor tidak langsung yang mempengaruhi kadar $\mathrm{Hb}$ ibu hamil meliputi: mayoritas ibu memiliki paritas sekundi (44.1\%), umur ibu mayoritas 20-30 tahun (79\%), frekuensi ANC ibu mayoritas > 4 kali $(85.3 \%)$, dan jarak kehamilan ibu mayoritas $>2$ tahun $(82.4 \%)$.

Simpulan: Hasil penelitian ini dapat disimpulkan bahwa terdapat beberapa faktor yang mempengaruhi kadar $\mathrm{Hb}$ ibu hamil yaitu faktor dasar, faktor langsung, dan tidak langsung.
\end{abstract}

Kata kunci: Faktor, hemoglobin, ibu hamil trimester III 


\begin{abstract}
Background: Anemia is one of the biggest causes of maternal mortality. Anemia that occurs until the third trimester can affect the condition of the fetus and the continuity of labor. The diagnosis of anemia in pregnant women is made by measuring hemoglobin levels in the mother's blood. This study aims to describe the factors that influence hemoglobin levels in third trimester pregnant women.

Method: This research uses quantitative descriptive method. This research was conducted in RW XIX Ngoresan Surakarta Community Health Center in September 2016 with 34 respondents. The instrument in this study is a questionnaire.

Results: Pregnant hemoglobin levels in Ngoresan Puskesmas area were $>10 \mathrm{gr} / \mathrm{dl}$ or normal (76.5\%). The basic factors that influence the hemoglobin levels of pregnant women include: mother's knowledge was good (41.2\%), most of mother's education was secondary education (94\%) and mother's socio-cultural who wasn't abstinence from food (85.3\%). Direct factors affecting hemoglobin levels of pregnant women included: all mothers consumed Fe tablets (100\%), most of mother nutritional status was good (79.4\%), all mothers did not have infectious diseases (100\%), and all mothers did not experience bleeding $(100 \%)$ Indirect factors that affect hemoglobin levels of pregnant women include: most of mothers have secundy paritas (44.1\%), most of mothers aged 20-30 years (79\%), mother have maternal ANC frequency> 4 times (85.3\%) and mother of maternal pregnancy> 2 years $(82.4 \%)$.

Conclusion: There are several factors that influence hemoglobin levels of pregnant women including basic factors, direct and indirect factors.
\end{abstract}

Keywords: Factor, hemoglobin, pregnant mother of third trimester

\section{PENDAHULUAN}

Angka Kematian Ibu (AKI) merupakan salah satu indikator derajat kesehatan di suatu negara. AKI di Indonesia tahun 2012 mencapai 359 per 100 ribu kelahiran hidup ${ }^{1)}$. Menurut World Health Organization, $40 \%$ kematian ibu di negara berkembang berkaitan dengan anemia dalam kehamilan $^{2)}$. Secara nasional, proporsi anemia pada ibu hamil sebesar $37,1 \%$ ). AKI Jawa Tengah tahun 2011 mengalami kenaikan dari tahun sebelumnya 104,97 per 100.000 kelahiran hidup menjadi 116,01 per 100.000 kelahiran hidup ${ }^{3)}$. Jumlah angka kematian ibu pada tahun 2014 menurut data Dinas Kesehatan Kota Surakarta mencapai 7 jiwa ${ }^{4}$.

Anemia pada kehamilan terjadi karena perubahan hematologi berupa peningkatan $45 \%$ volume plasma darah, peningkatan $25 \%$ massa eritrosit, terjadinya trombositopenia, terjadinya koagulasi, dan peningkatan kebutuhan eritropoiesis $^{5)}$.
Kasus anemia yang masih tinggi $\mathrm{u}-$ mumnya disebabkan oleh rendahnya kesadaran ibu hamil dalam memperhatikan pentingnya pencegahan anemia dan bahaya kekurangan asupan zat besi. Diagnosis ibu mengalami anemia ditegakkan melalui pengukuran kadar hemoglobin dalam darah $\mathrm{ibu}^{6)}$. Dari latar belakang tersebut peneliti tertarik mengambil judul penelitian faktor-faktor yang mempengaruhi kadar hemoglobin pada ibu hamil trimester tiga.

\section{SUBJEK DAN METODE}

Penelitian ini menggunakan deskriptif kuantitatif. Penelitian dilakukan di RW XIX wilayah kerja Puskesmas Ngoresan Surakarta. Waktu penelitian pada bulan September 2016. Populasi penelitian adalah seluruh ibu di wilayah kerja Puskesmas Ngoresan Surakarta. Teknik sampling dilakukan secara purposive sampling sebanyak 34 responden. Selanjutnya responden diberikan kuesioner tentang faktorfaktor yang mempengaruhi kadar hemo- 
globin pada ibu hamil, sedangkan pengukuran kadar hemoglobin dilakukan dengan alat ukur hemoglobin digital. Kriteria inklusi dalam penelitian ini meliputi ibu hamil trimester III dengan kondisi ibu dan bayi sehat, serta ibu bersedia menjadi responden.

HASIL
Tabel 1 menunjukan bahwa kadar
hemoglobin ibu hamil $>10$ gr/dl sebanyak

26 responden $(76,5 \%)$ sedangkan kadar hemoglobin ibu hamil < 10gr/dl sebanyak 8 responden $(23,5 \%)$.

Tabel 1. Kadar Hemoglobin Ibu Hamil

\begin{tabular}{cccl}
\hline $\mathrm{No}$ & $\mathrm{Hb}(\mathrm{gr} / \mathrm{dl})$ & $\mathrm{N}$ & \multicolumn{1}{c}{$\%$} \\
\hline 1 & $<10$ & 8 & 23,5 \\
2 & $>10$ & 26 & 76,5 \\
& Total & 34 & 100,0 \\
\hline
\end{tabular}

Sumber: Data Primer, 2017

Tabel 2. Faktor-Faktor yang Mempengaruhi Kadar Hemoglobin Ibu Hamil Trimester Tiga

\begin{tabular}{|c|c|c|c|c|c|}
\hline \multirow{2}{*}{$\begin{array}{l}\text { No } \\
1 .\end{array}$} & \multicolumn{2}{|c|}{ Faktor } & \multirow{2}{*}{$\begin{array}{l}\text { Tingkatan } \\
\text { Baik }\end{array}$} & \multirow{2}{*}{$\frac{\mathrm{n}}{14}$} & \multirow{2}{*}{$\begin{array}{c}\text { Persentase }(\%) \\
41,2\end{array}$} \\
\hline & Faktor Dasar & Pengetahuan & & & \\
\hline & & & Cukup & 12 & 35,3 \\
\hline & & & Kurang & 8 & 23,5 \\
\hline & & Pendidikan & Dasar & 1 & 3 \\
\hline & & & Menengah & 32 & 94 \\
\hline & & & Tinggi & 1 & 3 \\
\hline & & Pantangan Makanan & Ya & 5 & 14,7 \\
\hline & & & Tidak & 29 & 85,3 \\
\hline \multirow[t]{8}{*}{2.} & Faktor Langsung & Konsumsi Tablet Fe & $\mathrm{Ya}$ & 34 & 100 \\
\hline & & & Tidak & 0 & 0 \\
\hline & & Status Gizi & Normal & 27 & 79,4 \\
\hline & & & Tidak Normal & 7 & 20,6 \\
\hline & & Infeksi & Ya & 0 & 0 \\
\hline & & & Tidak & 34 & 100 \\
\hline & & Perdarahan & $\mathrm{Ya}$ & 0 & 0 \\
\hline & & & Tidak & 34 & 100 \\
\hline \multirow[t]{10}{*}{3.} & Faktor Tidak & Frekuensi ANC & $>4$ kali & 29 & 85,3 \\
\hline & Langsung & & $<4$ kali & 5 & 14,7 \\
\hline & & Paritas & Primi & 9 & 26,5 \\
\hline & & & Sekundi & 15 & 44,1 \\
\hline & & & Multi & 10 & 29,4 \\
\hline & & Umur Ibu Hamil & $<20$ tahun & 1 & 3 \\
\hline & & & $20-35$ tahun & 27 & 79 \\
\hline & & & $>35$ tahun & 6 & 18 \\
\hline & & Jarak Kehamilan & $<2$ th & 6 & 17,6 \\
\hline & & & $>2$ th & 28 & 82,4 \\
\hline
\end{tabular}

Sumber: Data Primer, 2017

Tabel 2 menunjukkan bahwa terdapat 14 responden $(41,2 \%)$ berpengetahuan baik dan 8 responden $(23,5 \%)$ berpengetahuan kurang. Terdapat 32 responden $(94 \%)$ berpendidikan menengah dan hanya 1 responden $(3 \%)$ berpendidikan dasar dan tinggi. Terdapat 29 responden $(85,3 \%)$ tidak menjalani tradisi pantang makan selama hamil dan hanya 5 responden $(14,7 \%)$ men- jalani tradisi pantang makan. Semua responden mengkonsumsi tablet Fe, tidak mengalami perdarahan, dan tidak menderita penyakit infeksi. Terdapat 27 responden $(79,4 \%)$ memiliki status gizi normal, sedangkan 7 responden $(20,6 \%)$ memiliki status gizi tidak normal. Mayoritas ibu hamil melakukan Antenatal Care (ANC) lebih dari 4 kali yaitu sejumlah 29 respon- 
den $(85,3 \%)$. Berdasarkan paritas, ibu hamil sekundi sebanyak 15 (44,1\%), dan primi sebanyak 9 (26,5\%). Mayoritas ibu hamil berada di usia reproduksi (20-35 tahun) yaitu sejumlah 27 responden (79\%). Terakhir, sebagian besar responden memiliki jarak kehamilan $>2$ tahun sebanyak 28 $(82,4 \%)$.

\section{PEMBAHASAN}

Berdasarkan hasil penelitian, faktor-faktor yang mempengaruhi kadar hemoglobin pada ibu hamil yaitu faktor dasar, faktor langsung, dan tidak langsung ${ }^{6)}$. Faktor dasar meliputi pengetahuan, pendidikan, dan sosial budaya. Tingkatan pengetahuan ibu mempengaruhi perilakunya. Semakin tinggi pengetahuannya, semakin tinggi kesadaran untuk mencegah terjadinya anemia. Tingkat pengetahuan ibu hamil juga akan mempengaruhi perilaku gizi yang berdampak pada pola kebiasaan makan yang pada akhirnya dapat menghindari terjadinya anemia. Tingkat pengetahuan ibu hamil dapat diperoleh dari pendidikan formal, informal, dan nonformal. Tinggi rendahnya pendidikan erat kaitannya dengan tingkat pengetahuan ibu tentang zat besi $(\mathrm{Fe})$ serta kesadarannya terhadap konsumsi tablet zat besi (Fe) selama hamil. Tingkat pendidikan ibu hamil yang rendah mempengaruhi penerimaan informasi sehingga pengetahuan tentang zat besi (Fe) menjadi terbatas dan berdampak pada kejadian anemia defisiensi besi. Faktor sosial budaya menjadi salah satu aspek yang berpengaruh terhadap kadar hemoglobin pada ibu hamil. Pendistribusian makanan dalam keluarga yang tidak berdasarkan kebutuhan untuk pertumbuhan dan perkembangan anggota keluarga, serta pantangan-pantangan yang harus diikuti oleh kelompok khusus misalnya ibu hamil, bayi, ibu nifas merupakan kebiasaan-kebiasaan adat istiadat dan perilaku masyarakat yang menghambat terciptanya pola hidup sehat di masyarakat $^{7)}$.

Faktor langsung yang mempengaruhi kadar hemoglobin pada ibu hamil meliputi konsumsi tablet $\mathrm{Fe}$, status gizi ibu hamil, penyakit infeksi, dan perdarahan. Kebutu- han Fe cukup tinggi karena selain diperlukan untuk janin dan plasenta juga karena adanya proses retensi air atau penambahan cairan sebanyak $40 \%$ dalam tubuh ibu. Jumlah $\mathrm{Fe}$ yang dianjurkan adalah 18 $\mathrm{mg} /$ hari. Kebutuhan tersebut sulit diperoleh dari sumber makanan saja tanpa penambah zat besi dalam makanan ${ }^{8)}$. Mengatasi masalah ini, WHO menganjurkan untuk memberikan suplementasi zat besi pada ibu hamil. Setiap ibu hamil diharapkan meminum paling sedikit 90 tablet selama hamil $^{2)}$. Status gizi berkaitan dengan ketahanan pangan keluarga. Setiap keluarga diharapkan mampu memenuhi kebutuhan pangan seluruh anggota keluarganya dalam jumlah yang cukup baik jumlah maupun mutu gizinya. Seseorang yang tidak memperoleh cukup makan, maka daya tahan tubuhnya akan melemah dan mudah terserang penyakit. Makanan dan penyakit dapat secara langsung menyebabkan gizi kurang. Timbulnya gizi kurang tidak hanya dikarenakan asupan makanan yang kurang, tetapi juga karena penyakit. Penyebab anemia gizi besi juga dikarenakan terlampau banyaknya besi keluar dari badan misalnya perdarahan selama proses kehami$\operatorname{lan}^{7)}$.

Faktor tidak langsung meliputi frekuensi ANC, paritas, umur ibu, dan jarak kehamilan. Salah satu tujuan pemeriksaan ANC adalah mengenali dan menangani penyakit yang menyertai kehamilan ${ }^{9)}$. Cakupan pelayanan antenatal dapat dipantau melalui kunjungan ibu hamil. Pelayanan standar paling sedikit 4 kali kunjungan dengan distribusi sekali pada triwulan pertama (K1), sekali pada triwulan kedua (K2), dan dua kali pada triwulan ketiga (K4). Jadi, total kunjungan ANC adalah 4 kali kunjungan ${ }^{10)}$. Melalui pemeriksaan ANC ibu dapat memperoleh penyuluhan kesehatan yang berhubungan dengan kehamilan seperti penyuluhan gizi dan makanan, serta mendapatkan tablet tambah darah dari petugas kesehatan dimana konsumsi tablet tambah darah akan memperkecil terjadinya anemia dalam kehamilan ${ }^{7)}$. Paritas juga mempengaruhi kadar hemoglobin pada 
ibu hamil. Semakin sering seorang wanita mengalami kehamilan dan melahirkan, maka akan semakin banyak kehilangan zat besi dan menjadi semakin anemia ${ }^{11)}$. Anemia bisa terjadi pada ibu dengan paritas tinggi terkait dengan keadaan biologis ibu dan asupan zat besi. Paritas lebih berisiko bila terkait dengan jarak kehamilan yang pendek. Umur <20 tahun dapat menyebabkan anemia karena pada umur tersebut perkembangan biologis dalam hal ini alat reproduksi belum optimal. Psikis belum matang pada usia $<20$ tahun, hal itu menyebabkan wanita hamil mudah mengalami guncangan mental yang mengakibatkan kurangnya perhatian terhadap pemenuhan kebutuhan zat-zat gizi selama kehamilannya. Kehamilan >35 tahun juga merupakan kehamian berisiko tinggi. Wanita yang hamil dalam usia yang terlalu tua akan rentan terhadap anemia karena penurunan daya tahan tubuh sehingga mudah terkena berbagai infeksi selama kehami$\mathrm{lan}^{12)}$. Masa reproduksi yang sehat dan kurang resiko dengan komplikasi kehamilan adalah usia 20-35 tahun, sedangkan kehamilan berisiko adalah usia $<20$ dan $>35$ tahun $^{13)}$. Kehamilan menyebabkan cadangan bezi berkurang dan diperlukan waktu 2 tahun untuk mengembalikan cadangan besi ke tingkat normal dengan syarat bahwa selama masa tenggang waktu tersebut kesehatan dan gizi ibu dalam kondisi yang baik. Sebaiknya jarak persalinan terakhir dengan jarak persalinan berikutnya minimal 2 tahun $^{14)}$.

\section{SIMPULAN DAN SARAN}

\section{Simpulan}

Berdasarkan hasil penelitian dapat dsimpulkan bahwa:

1. Kadar hemoglobin ibu hamil di wilayah Puskesmas Ngoresan mayoritas $>10 \mathrm{gr} / \mathrm{dl}$ atau normal.

2. Faktor dasar yang mempengaruhi kadar hemoglobin ibu hamil meliputi pengetahuan, pendidikan dan sosial budaya.

3. Faktor langsung yang mempengaruhi kadar hemoglobin ibu hamil meliputi konsumsi tablet $\mathrm{Fe}$, status gizi, penyakit infeksi, dan perdarahan.

4. Faktor tidak langsung yang mempengaruhi kadar hemoglobin ibu hamil meliputi frekuensi ANC, paritas, umur ibu, dan jarak kehamilan.

\section{Saran}

Perlu dilakukan analisis lebih mendalam terkait faktor-faktor yang mempengaruhi kadar hemoglobin pada ibu hamil sehingga dapat diketahui faktor mana yang dominan mempengaruhi dan besarannya

\section{DAFTAR PUSTAKA}

1. Depkes RI (2013). Profil Kesehatan Indonesia

2013

http://www.depkes.go.id/ (Diakses

November 2015)

2. Saifuddin AB (2011). Ilmu kebidanan. Edisi 3. Jakarta : Yayasan Bina Pustaka Sarwono Prawirohardjo. pp: 182-84: 356-8: 213: 858-65.

3. Dinkes Jawa Tengah (2014). Buku Saku Kesehatan Tahun 2013.

4. http://www.dinkesjatengprov.go.id/ (Diakses Januari 2016).

5. Dinkes Kota Surakarta (2013). Profil Kesehatan Kota Surakarta. Surakarta: Dinkes.

6. Hoffbrand AV, Pettit JE, Moss PAH (2005). Kapita selekta hematologi Ed 4. pp: 11-25.

7. Asrina, Suhartatik, Ferial EW (2014). Faktor-faktor yang berhubungan dengan kejadian anemia pada ibu hamil di rumah sakit ibu dan anak siti fatimah makassar. Jurnal ilmiah kesehatan diagnosis. Vol.4, No.6. pp: 1-5.

8. Asyirah S (2012). Faktor-Faktor yang Berhubungan dengan Anemia pada Ibu Hamil di Wilayah Kerja Puskesmas Bajeng Kecamatan Bajeng Kabupaten Gowa Tahun 2012. Depok: FKM UI.

9. Susiloningtyas I (2012). Pemberian tablet besi (fe) dalam kehamilan. Semarang: Universitas Islam Agung Semarang. pp: 4-9. 
10. Hutahaean S (2013). Perawatan antenatal. Jakarta: Salemba Medika. pp: 55-65.

11. Prawirohardjo S (2009). Ilmu kebidanan. Edisi 4. Jakarta: Yayasan Bina Pustaka Sarwono Prawirohardjo. pp: 182-84: 356-8: 213: 858-65.

12. Proverawati A (2011). Anemia dan anemia kehamilan. Yogyakarta: Nuha Medika. pp: 119.

13. Amirudin, Wahyuddin (2006). Studi Kasus Kontrol Faktor Biomedis Terhadap Kejadian Anemia Ibu Hamil di Puskesmas Bantimurung Maros,
Vol. 25 No. 2. Jurnal Medika Nusantara.

14. Adi DI, Syam A, Nurrochimawati S (2012). Edukasi gizi terhadap pola konsumsi ibu hamil anemia dalam upaya perbaikan kadar hemoglobin di puskesmas sudiang raya makassar. Media Gizi Masyarakat Indonesia. Vol.2, No.1.pp: 18-20.

15. Suwarni S (2013). Pengaruh pemberian suplemen besi dan vitamin $c$ terhadap daya tahan aerob dan kadar hemoglobin. Jurnal Pasca Sarjana: Universitas Sebelas Maret. Vol.1, No.2. pp: 1-9. 